\title{
A Review of Factors Affecting Workplace Training Transfer and Its Effectiveness
}

\author{
Effulgence \\ Vol. 16 (Special Issue) \\ January - June, 2018 \\ Rukmini Devi Institute of Advanced Studies \\ E-mail: effulgence@rdias.ac.in, Website : www.rdias.ac.in \\ http://effulgence.rdias.ac.in/user/default.aspx \\ https://dx.doi.org/10.33601/effulgence.rdias/v16/iSpl1/2018/article0.12
}

K ushi Sharma, K ushi Sharma, Research Scholar, School of M anagement, Gautam Buddha U niversity, Greater Noida, India, E mail id- kushisharma12@ gmail.com

Dr. Neeti Rana, Dr. N eeti Rana, Associate Professor, School of M anagement, Gautam B uddha University, Greater Noida, India, E mail id-neeti@gbu.ac.in

\begin{abstract}
Purpose- The purpose of this research paper is to present a novel approach to transfer of training in organisations. A review of studies assessing transfer of training for various training programs are presented.

Design- The paper's approach is theoretical and the methodology used is literature review of research papers focusing on transfer of training.

Findings- Transfer of training occurs in a specific work context. Once trainees return to their work places, they are confronted with their work environment This paper seeks to identify the various factors that affect transfer of training. It primarily gives an idea about the elements of the climate of transfer of training. V arious researches have identified supervisor and peer support as major dimensions for training transfer Motivation to transfer also plays an important role in training transfer $M$ anagerial implications The research seek to assist training and development professionals undertake more robust and efficient training evaluations. The paper discusses about training outcomes in the form of knowledge which is transferred. The findings could help HR professionals developing training programs more effectively.
\end{abstract}

Scope of future work- Organisations substantially invest in organisational training but there is a lack of evaluation activity. Empirical research can be done on how transfer activities are related to effective evaluation and post training self efficacy. Limitations- The research does not study how transfer of training is related to various organisational issues like turnover and absenteeism, employee commitment and productivity etc.

Key words- training transfer, effectiveness, capability, work environment, transfer motivation

\section{INTRODUCTION}

The importance of training and development programmes have been acknowledged widely. If the various factors that design the process, identifies the reactions, transfer and application and utility of learning in a workplace are not thoroughly identified and understood evaluations of training programmes will not be very accurate.
A ccording to Goldstein, "most organisations do not collect the information to determine the utility of their own training programs".

Learning transfer is one of the most useful and a continuous process to apply newly gained attitudes, knowledge and skills into the workplace. Organisations cannot depend on trainee reactions solely for the evaluation of effectiveness of trainings. There are other dimensions which need to be studied for a more reliable result of learning evaluations. A nd one of those major dimensions are training transfer. 
Its a generalization that trainee satisfaction can actually identify the effectiveness of training while in reality it may impact training effectiveness but there are several other factors including behaviour exhibited by the trainee on the job. Work place behavior of the employee is dependent on settings of the job, people, and situation.

Training programmes conducted by the organisations are costly from the perspective of organisational time and money (Steensma and Groenveld, 2010)

Training is considered as one of the most important contributions to human resources development, and is definitely beneficial for the employees' growth. In order to make training equally beneficial and relevant for the organisation, there is a need to transfer the training in the workplace. If learning is being transferred to the organisation it will lead to the competitive advantage of the company. (Saks \& B urke, 2014)

HR Practitioners should consider evaluation of the investments of the organisation in employee training and learning and there are reasons to it. There is the need to justify budgetary allocations and time given to a particular activity. Legal requirements for training should be considered, organisations should identify the opportunity cost of investing in one training programme compared to another. A decision is to be taken whether a programme should be continued and the reinforcement of prior learning should be done. Organisations need to identify ways of improving programmes, assessing whether training is enhancing employee's knowledge, efficacy and skills. Organisations need to assess whether training is the appropriate response to a performance need. (A ragon-Sanchez et al., 2003;
Spitzer, 2005; Wang and Wilcox, 2006; Berge, 2008; Giangreco et al., 2010; Steensma and Groenveld, 2010

\section{OBJECTIVES}

The research paper aims to understand the importance of training transfer for the organisations. This study identifies the factors which are important for transfer of training.

\section{METHODOLOGY}

A literature review of studies assessing importance of training transfer and factors responsible for training transfer for various organisational training programs are presented. The approach of the paper is theoretical

\section{REVIEW OF LITERATURE}

If the trainees are able to pass a post training test, it surely does not mean that the training transfer has been successfully done (Sims, 1993)

Few organisations do evaluation to study the impact of training specially training transfer into the workplace and also the impact on organisational performance (Sugrue and Rivera, 2005; Scourtoudis and Dyke, 2007; Blanchard and Thacker, 2007; Velda et al., 2007; A guinis and K raiger, 2009;)

In the training transfer process trainee characteristic plays an important role. It also provides useful insights regarding the designing of the training program and overall management are equally important. Trainee characteristics also helps in design and management of training programs. (I rene Nikandrou V assiliki Brinia Elissavet Bereri, 2009) 
Figure 1 Training alone

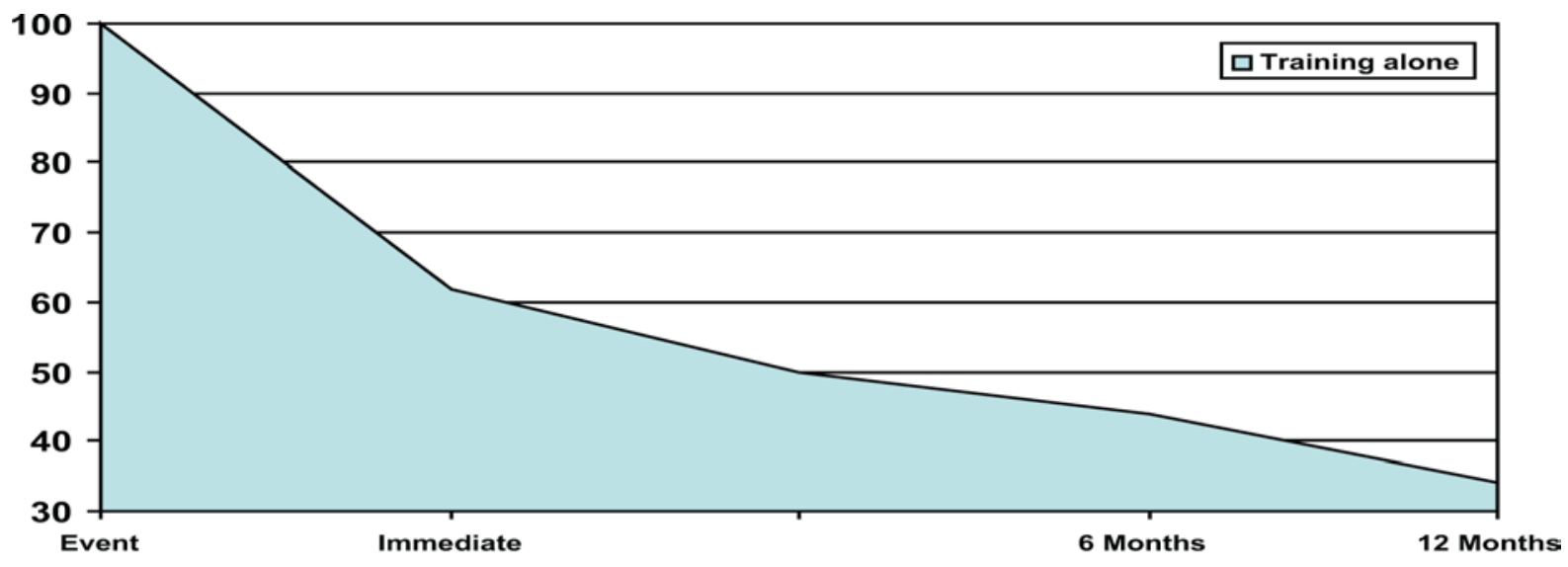

Source: Saks and Belcort (2006)

Theoretical frameworks of training have suggested that trainee's motivation to transfer has a major impact on training transfer. If the trainee has a desire to apply learned skills and knowledge on the job, only then he can apply training in to practice (Gegenfurtneact pre at al., 2009; N oe, 1986)

Noe (1986) defined motivation to transfer as "a trainee's desire to use the knowledge and skills mastered in the training program on the job"

If the various factors and contexts that decide the transfer and application of learning in a workplace are not thoroughly understood learning evaluations of training programmes cannot be successful. $M$ ann and Tamkin criticised Donald Kirkpatrick's "four levels" training evaluation approach. It was observed that Kirk Patrick's M odel is often seen as a model of evaluating workplace learning but actually this is not in fact the case. This sometimes does not create proper foundation for training eval uations (M ann, 1996; T amkin et al., 2002).

Few organisations evaluate the impact of training and in particular training transfer into the workplace and also the impact on performance (Sugrue and Rivera, 2005; Scourtoudis and Dyke, 2007; Blanchard and Thacker, 2007; V elda et al., 2007; A guinis and Kraiger, 2009;). A ccording to Spitzer (2005) the situation where training transfers are not been identified properly is a situation of "crisis". Evaluation activities mostly focuses on learning rather than performance outcomes (Cassidy et al., 2005; Leimbach, 2010)

Trainee's affective reactions are not studied properly in most of the evaluations (B rown, 2005). This is considered as a narrow view of training (Guerci and V inante, 2011). The major objective of employer-led learning is to increase organisational performance (Sanderson, 1995). If the trainees are able to pass a test, does not mean that the learning transfer has been done effectively (Sims, 1993). Organisations increasingly judge success of training on the basis of how does training effects long-term performance of the trainees ( $W$ ang and Wilcox, 2006; B erge, 2008)

Learning is operationalised in social environments (Holly and Rainbird, 2001). Studies suggests that only 10-15 per cent of training which is learnt in the classroom is actually transferred into the workplace (Velda et al., 2007). A cquiring new knowledge, skills and attitudes (KSA) with the help of a learning activity is not enough for a successful training. KSAs need to be learned, applied and maintained while working in the organisation. Transfer also depends on certain situational factors like goal setting, work pressure, peer support, supervisor coaching, organisational support, employee motivation, job expectations and opportunity apply the training (Burke and Hutchins, 2007).

Transfer of training occurs when employees are back to their work. Trainees are confronted with 
their work environment when they return to their workplace (Grossman \& Salas, 2011)

Research has suggested that supervisor and peer support are the major dimensions which affect transfer of training (e.g. Holton et al., 2000; $V$ an den B ossche et al., 2010).

M otivation to transfer plays an important role in conceptual models of transfer of training in the work environment (e.g. Holton, 2005; N oe, 1986)

Individual and team perceptions of supervisor and peer support relate positively to individual and team perceptions of motivation to transfer. Perceptions of motivation to transfer relate positively to training transfer. There will be indirect effects from individual and team perceptions of supervisor and peer support on training transfer through individual and team perceptions of motivation to transfer. ( Ann-Christine Massenberg, Daniel Spurk and Simone Kauffeld, 2015)

Individuals often work in teams, and therefore it is necessary to analyze the team level and not to ignore possible shared perceptions within teams (Chen \& K limoski, 2007).

F igure $2 \mathrm{M}$ ultilevel indirect effect model

(Ann-Christine M assenberg, Daniel Spurk and Simone K auffeld , 2015)

Team level perceptions

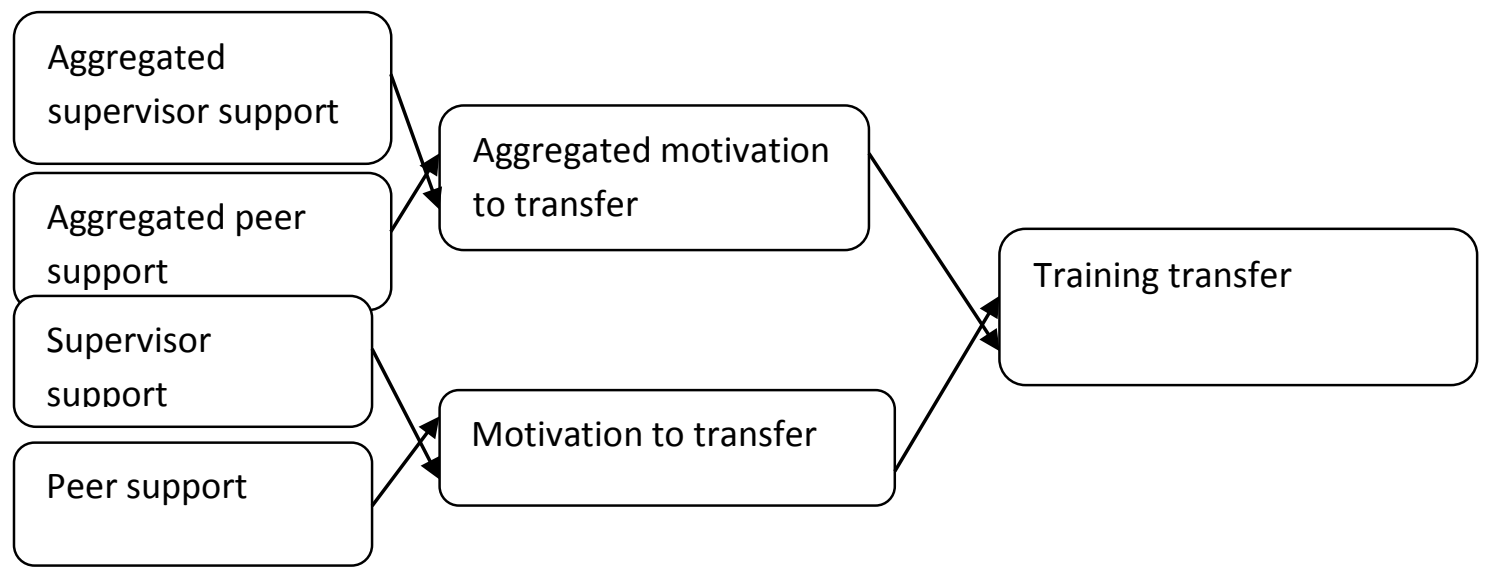

Individual level perceptions

Social support is an important antecedent for training which includes supervisor and peer support. Supervisors and peers play very diverse roles for employees in the social interaction with the trainee ( $V$ an den B ossche et al., 2010).

The expected outcome of training is transfer of learning because transfer is application of the skills learned during training. If application is not being done into practice, all the efforts done for training are worthless (e.g. Laker \& Powell, 2011).

Research has demonstrated that if trainees' motivation to transfer exists then definitely the application of new skills to the workplace will take place. There is always a positive relationship between motivation to transfer and application of learned skills (e.g. A xtell et al., 1997; B ates et al., 2007; K auffeld et al., 2008). 
Figure $3 \mathrm{~K}$ ey factors in transfer

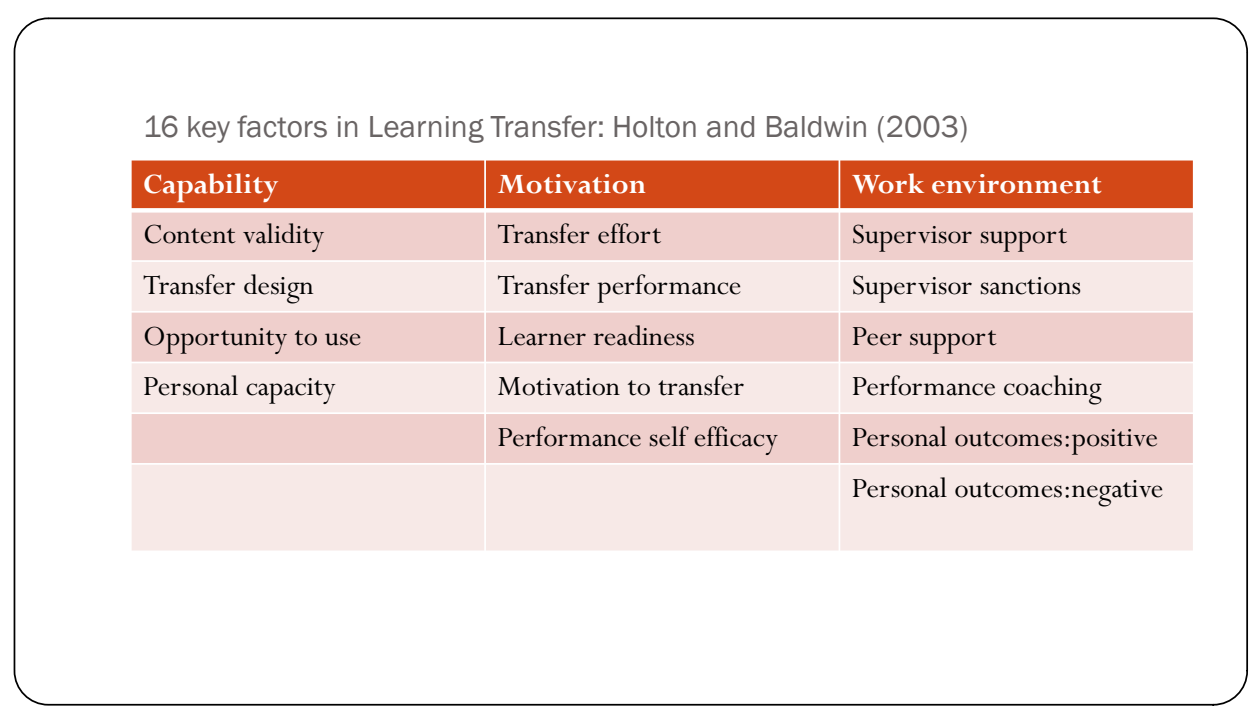

A ccording to Holton and Baldwin (2003) there are 3 major factors of transfer of training- capability, motivation and work environment.

Some research studies suggests that fact that very little of what was learned during a training programme was used at the workplace (Broad and N ewstrom, 1992 apud. Saks and B urke, 2012)

A conceptual model was given by Griffin which was an evaluation framework which identifies the various elements that affect the planning, delivery and transfer of training in the organisation. The model gives a full picture and explains how various elements of training evaluation are linked to each other. It provides evaluators with a foundation to carry out diverse evaluations in the workplace ( Griffin, 2011).

A positive reaction towards a training programme cannot guarantee that learning will occur in the training programme, in the same way superior performance during training does not al ways result in similar behaviour in the work setting. The study reported later in this article is concerned with the maintenance of behaviour change or improved job performance following training and draws on literature on transfer of training issues. Transfer of training is defined as the "degree to which trainees effectively apply the knowledge, skills and attitudes gained in a training context to the job"

learner control is high in the case of online training, hence a stronger relationship exists between trainee reactions and cognitive learning outcomes (Sitzmann et al., 2003).

Some organizations have approached online learning in a blended format to allow for instructor participation. Blended learning mixes a traditional classroom setting with online learning activities, training content delivery and communication (Tang and B yrne, 2007).

It was found that while trait is one of the measures, learning states plays an important role in training transfer. B lume et al.'s (2010)

Towler et al.'s (2014) explained that if leaders are effective they create a positive climate for the trainees. If leaders show discretionary behaviours employees show increased interest in learning during training program.

Schindler \& Burkholder (2016) gave a new direction to training transfer. They identified support during and after training is a multidimensional construct which includes social support and task support. M entoring and coaching were also found to be important variables of support.

Transfer of learning is one of the oldest fields explored by the researchers. Its an extensive field which needs more researches. (B ell et al. 2017)

According to Huang \& Bramble (2016) trait and state plays an important role in a trainee-controlled computer-based training program. They found that if task demands are dynamic and versatile more 


\section{MODEL DESCRIPTION}

On the basis of the literature review following model has been developed-

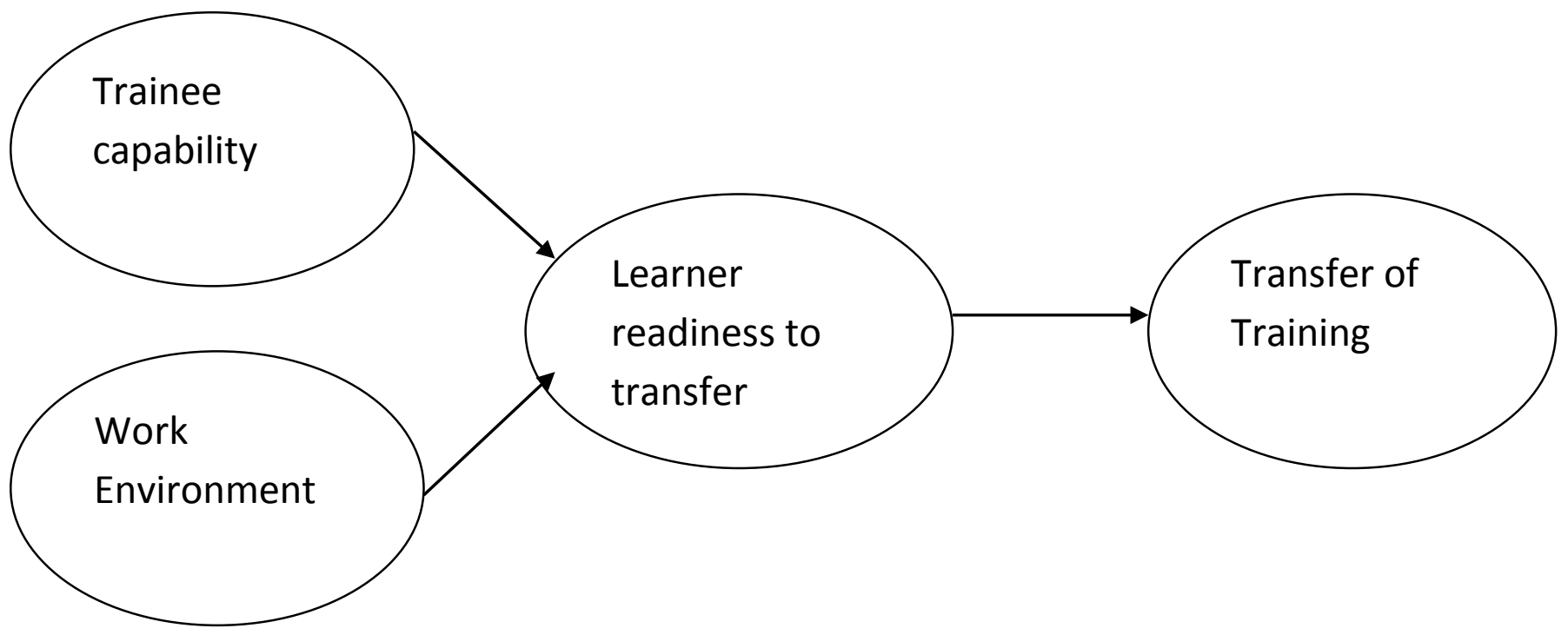

Two major predictors were identified which leads to learner readiness to transfer training. Learner readiness to transfer will finally lead to transfer of training. Learner readiness is related to motivation to transfer. Trainee capability includes personal capacity and personality of the trainee while work environment includes supervisor support and peer support. All the factors are equally important for transfer of training.

\section{SCOPE OF FUTURE RESEARCH}

Training transfer is still an emerging field. The future research may focus on how work group support is related transfer of training. More research is needed on post training interventions to study the real impact of training on transfer and performance. Support is a multidimensional construct which can be explored with the help of other aspects of support.

\section{CONCLUSION}

Effective training transfer is considered to be a very complex activity, thus identifying individual factors and situational factors which may increase or decrease the rate of transfer is a major task. Transfer is considered to be a vehicle which leads to meaningful changes in work performance and effectiveness. There are two major conditions for training transfer, first is skills and knowledge has been learned and second is retention of learned skills and knowledge so that it can be applied on the job.

Factors Various researches have identified supervisor and peer support as major dimensions for training transfer $M$ otivation to transfer is related to the trainee, if trainee is motivated after training transfer will be easier. Personal capacity and opportunity to use training also plays important roles in transfer of training. Training design and learning principles were always considered as major issues for training effectiveness. Trainee characteristic and supportive work culture were found to effect training positively. Although most of the transfer studies have been done on individuals but some studies on team training suggests that team coordination and adaptation training leads to better results in terms of transfer. Transfer of training is one of the oldest fields in human resource development field and there are many areas where exploration is required.

\section{BIBLIOGRAPHY}

1) Ana-Inés Renta-Davids, José-M iguel Jiménez-González, Manel Fandos- 
Garrido, Ángel-Pío GonzálezSoto, (2014),"T ransfer of learning: M otivation, training design and learning-conducive work

a. effects", European Journal of Training and Development, $\mathrm{V}$ ol. 38 Iss 8 pp. 728-744

2) Anna Grohmann and Simone Kauffeld, (2013), "Evaluating training programs: development and correlates of the Questionnaire for Professional Training Evaluation", International Journal of Training and Development 17:2, pp 135155

3) Arthur W. Jr.,DDay,Villado G., GlazeM,SchuelkeB, Kowolik Bennet W. (2013) A comparative investigation of individual and team skill retention and transfer on a complex command-andcontrol simulation task. See Arthur et al. 2013b, pp. 321-43

4) Baldwin TT, Ford JK, Blume B.D., (2009)T ransfer of training , International Review of Industrial and Organizational Psychology, V ol. 24, ed. GP Hodgkinson, JK Ford, pp. 41-70

5) Baldwin Timothy T., Ford J. Kevin, Blume Brian D., (2017) The State of Transfer of Training Research: Moving Toward M ore Consumer-Centric Inquiry , Human resource development quarterly, pp 1-12

6) B eer M, Finnstrom M, Schrader D. 2016. Why leadership training fails- and what to do about it. Harv. Bus. Rev. 94(10):5057

7) B rown TC, W arren AM, K hattar V. 2016. The effects of different behavioral goals on transfer from a management development program. Hum. Resour. Dev. Q. 27:349-72

8) Cascio WF, Montealegre R. 2016. How technology is changing work and organizations. A nnu. Rev. Organ. Psychol. Organ. B ehav. 3:349-75

9) ChiaburuDS,SawyerK $B,(2010)$

Transferring more than learned in training: employees' and managers' (over)generalization of skills. Int. J. Sel. A ssess. 18:380-93

10) Fiona Robson Sharon Mavin, (2014),"Evaluating training and development in UK universities: staff perceptions", European Journal of Training and Development, Vol. 38 Iss 6 pp. $553-569$
11) Ford J. Kevin, Baldwin Timothy P., Prasad Joshua, (2017) Transfer of Training: The Known and the Unknown, A nnual Review of Organizational Psychology and Organizational Behavior, pp 5.1-5.25

12) Grossman Rebecca, Burke Smalley, Lisa A., (2017), Context-dependent accountability strategies to improve the transfer of training: A proposed theoretical model and research propositions Human Resource $M$ anagement Review

13) Harshit Topno, (2012), Evaluation of Training and Development: An A nalysis of $V$ arious Models, Journal of Business and $M$ anagement (IOSR-JBM) ISSN: 2278-487X. V olume 5, Issue 2,. PP 16-22

14) Pilar Pineda ,(2010),"Evaluating a training using the "four levels model" ", J ournal of Workplace Learning, Vol. 22 Iss 5 pp. 319-331

15) Sambedna J ena Chandan Kumar Sahoo, (2012)"exploring competency requirements towards superior managerial performance: a theoretical construct" , employment relations record, vol 12 no 2, pp 19-37

16) Sanchez Ron, (2004), Understanding competence-based management Identifying and managing five modes of competence, Journal of Business Research, 57, pp 518-532

17) Seema Singh, Impact and Effectiveness of Corporate Training Programs through Industry Academia Tie-Ups, Journal of Commerce \& $\mathrm{M}$ anagement Thought $\mathrm{V}$ ol. 7-2, 2016, pp 309-319

18) Sue Lancaster, Lee Di Milia, (2014),"Organisational support for employee learning: An employee perspective", European Journal of Training and Development, Vol. 38 Iss 7 pp. 642-657

19) Tasca orge Eduardo, Leonardo Ensslin Sandra Rolim Ensslin, M aria Bernardete Martins Alves, (2010),"An approach for selecting a theoretical framework for the evaluation of training programs", Journal of European Industrial Training, $\mathrm{V}$ ol. 34 Iss 7 pp. $631-655$

20) Thomas G. Reio Jr., Faye C. Sutton, (2006) "E mployer A ssessment of WorkRelated Competencies and Workplace A daptation", HUMAN RESOURCE DEVELOPMENT QUARTERLY, vol. 17, no. 3, pp 305-322 